\title{
Carboxymethyl Cellulose-Graft-Polyacrylic Acid Hydrogel: A Cost Effective and Reusable Adsorbent for $\mathrm{Cu}^{2+}$
}

\author{
A. Salama", Nadia Shukry, I. M. El-Sherbiny ${ }^{*}$ and A. Sarhan* \\ Cellulose and Paper Department, National Research Center, \\ 33 Bohouth St. Dokki, Giza 12622 and *Polymer Laboratory, \\ Chemistry Department, Faculty of Science, Mansoura \\ University, ET-35516 Mansoura, Egypt.
}

\begin{abstract}
A POROUS hydrogel composed of carboxymethyl cellulose grafted with polyacrylic acid CMC-g-PAA was prepared, by using methylenebisacrylamide (MBA) as crosslinking agent and ammonium persulfate (APS) as initiator. CMC-g-PAA hydrogel was evaluated as an adsorbent for removal of divalent copper ions from waste water. The effect of different adsorption parameters such as $\mathrm{pH}$, contact time and initial copper ion concentration on removal process from aqueous solution was investigated. Adsorption isotherms for $\mathrm{Cu}^{2+}$ well fitted the Langmuir equation with maximum adsorption capacity $471 \mathrm{mg} / \mathrm{g}$. The kinetics of adsorption process are appropriate to be described with pseudo second order model. The high adsorption capacity and kinetic results prove that CMC-g-PAA can be potentially used as a cost effective adsorbent to remove heavy metals from aqueous solutions.
\end{abstract}

Keywords: Carboxymethyl cellulose, Hydrogel, $\mathrm{Cu}^{2+}$ removal and Adsorption.

Heavy metal ions contaminating waste water is of great concern because of the harmful, acute and even fatal effect to the human beings ${ }^{(1,2)}$. Recent evidence shows that excessive consumption of copper can cause nausea, vomiting, respiratory difficulties, liver and kidney failure ${ }^{(3,4)}$. Conventional technologies for the removal of heavy metal ions from aqueous solutions like chemical precipitation, ion exchange, chemical oxidation/reduction, reverse osmosis and ultrafiltration have inherent disadvantages, such as less efficiency, high costs and further generation of toxic sludge or other waste products ${ }^{(5)}$. Therefore, searching for cheaper, higher efficient and more environment-friendly technologies are attracting considerable attention of scientists.

Adsorption process is emerging as an alternative to conventional methods for the effective removal of heavy metal ions and organic pollutants from effluent $^{(6-8)}$. Recently, a great deal of attention has been directed towards the production of bioadsorbents from natural polymers, such as $\operatorname{starch}^{(9)} \operatorname{lignin}^{(10)}$, cellulose $^{(1,8,11,12)}$, chitin/chitosan ${ }^{(13,14)}$ and agricultural wastes ${ }^{(15)}$. These bioadsorbents are renewable and have many advantages over traditional

\# Corresponding author: Email: ahmed_nigm78@yahoo.com 
adsorbents, such as cost-effective, biodegradability, non toxicity, environmentally friendly materials, hydrophilicity and good reusability ${ }^{(15-17)}$.

Hydrogels are cross-linked networks of hydrophilic polymers physically and/or chemically cross-linked to prevent their dissolution ${ }^{(18)}$. The porous structure for these materials, facility of the incorporation of different chelating groups, high internal surface area and high water content are extremely suitable properties to adsorb organic toxic materials and heavy metals ${ }^{(13)}$. Polysaccharides have been used for preparing a promising hydrogels for removal of metal ions $^{(16,17,19)}$.

The present article represents an optimized synthesis of a superabsorbent hydrogel via crosslinking graft polymerization of acrylic acid onto carboxymethylcellulose. The grafting of acrylic acid, an anionic comonomer, will increase the anionic carboxyl group's density which is capable of forming complexes with $\mathrm{Cu}^{2+}$ ions. The adsorption isotherms were evaluated to elucidate the adsorption mechanism and adsorption capability of the hydrogel. Moreover, the adsorption capacity and the kinetic of copper adsorption on the CMC-g-PAA hydrogel were studied.

\section{Materials}

\section{Experimental}

CMC sodium salt (> 99.5\%) with high viscosity was purchased from Fluka BioChemika. The viscosity of $4 \% \mathrm{CMC}$ in water at $25{ }^{\circ} \mathrm{C}$ is $1000-1500 \mathrm{mPaS}$. Acrylic acid $(99 \%)$ and $\mathrm{N} \mathrm{N}^{\prime}$-methylenebisacrylamide were purchased from Sigma Aldrich and used without further purification. The other chemicals, potassium persulphate and copper sulphate hexahydrate were analytical grade and used as received.

\section{Preparation of CMC - $g$-PAA hydrogels}

Graft copolymerization of AA onto CMC using MBA as chemical crosslinker, was carried out according to the following steps: $0.2 \mathrm{~g} \mathrm{CMC} \mathrm{in} 10 \mathrm{ml}$ double distilled water was mixed with different concentrations of $\mathrm{AA}$ and different concentrations of MBA. After bubbling $\mathrm{N}_{2}$ gas for $20 \mathrm{~min}$ to deoxygenate the solution, APS as a redox initiator was added to the solution and then the mixture was heated until the gelation was completed. The resulting hydrogel was cut into disks and immersed in an excess amount of double distilled water for 3 days to remove the residual unreacted monomers. Swollen hydrogels were dried in a vacuum oven for 2 days at $30^{\circ} \mathrm{C}$ to a constant weight.

\section{Swelling studies}

Swelling experiments of the CMC-g-PAA hydrogel were carried out in distilled water. A cubic sample of hydrogel with average size $(2 \times 2 \times 2) \mathrm{mm}$ was immersed in distilled water until equilibrium swelling was attained. The swollen weights of the hydrogel were determined, after removal of the surface liquid using tissue paper. The percent swelling was calculated by the following equation: 


$$
\left.\left.\% \text { Swelling=100[( } \mathrm{W}_{\mathrm{t}}-\mathrm{W}_{0}\right)\right] / \mathrm{W}_{0}
$$

where $W_{0}$ is the initial weight and $W_{\mathrm{t}}$ is final weight of the film at time $t$.

Adsorption experiments of $\mathrm{Cu}^{2+}$ ions

Stock solution of $\mathrm{Cu}^{2+}$ ions (1000 ppm) was prepared using $\mathrm{CuSO}_{4} \cdot 6 \mathrm{H}_{2} \mathrm{O}$. The stock solution was then diluted to make solutions with desired concentrations. Batch adsorption experiments were conducted at room temperature in $100 \mathrm{ml}$ bottles with continuous stirring by a magnetic stirrer. $50 \mathrm{mg}$ CMC-g-PAA were immersed in $100 \mathrm{ml}$ solution with continuous stirring. After filtration, the concentration of $\mathrm{Cu}^{2+}$ remained in the solutions was determined by atomic absorption spectrophotometer PERKIN-ELMER 2380. Effect of $\mathrm{pH}$ on $\mathrm{Cu}^{2+}$ ion adsorption was investigated in the $\mathrm{pH}$ range 2-6 in solution with initial $\mathrm{Cu}^{2+}$ ions concentration of $100 \mathrm{ppm}$. The $\mathrm{pH}$ values selected in the experiments were chosen prior to the precipitation limit of the copper ions $(\mathrm{pH}=6)$. The buffer solutions used for adjusting the $\mathrm{pH}$ of the medium were $\mathrm{KCl} / \mathrm{HCl}(\mathrm{pH} 2$ and 3$)$ and acetic acid/sodium acetate ( $\mathrm{pH} 4,5$ and 6). The CMCg-PAA gel was equilibrated at the certain $\mathrm{pH}$ for about $4 \mathrm{hr}$ before the addition of $\mathrm{Cu}^{2+}$ ions. The amount of copper ion adsorbed on the hydrogel at adsorption equilibrium, $q_{e}(\mathrm{mg} / \mathrm{g})$, was calculated according to the following equation:

$$
q_{e}=\frac{(c o-c e) \mathrm{v}}{\mathrm{w}}
$$

where $\mathrm{C}_{0}$ and $\mathrm{C}_{\mathrm{e}}$ are the initial and equilibrium metal ion concentrations (mg/L), $\mathrm{V}$ is the volume $(\mathrm{L})$ of the metal ion solution used in the adsorption experiment, and $\mathrm{W}$ is the weight of the hydrogel disc $(\mathrm{g})$. Data are representative of at least three experiments, and standard deviations are less than $6.0 \%$.

Desorption and reusability behaviors of CMC - $g-P A A$ hydrogel

A total of $50 \mathrm{mg}$ of dry hydrogel discs were added to $100 \mathrm{ml}$ of metal ion solution $(200 \mathrm{mg} / \mathrm{L})$, and the mixture was agitated continuously at the optimum $\mathrm{pH}$ and equilibrium time to reach its adsorption equilibrium. The hydrogel discs were then withdrawn from the solution and washed with deionized water 3 times. Thereafter, the hydrogel discs were immersed into $\mathrm{HNO}_{3}$ solution $(0.5 \mathrm{M})$ for $2 \mathrm{hr}$ under stirring to remove the adsorbed metal ions from the hydrogel and then treated with $0.01 \mathrm{M} \mathrm{NaOH}$ for $8 \mathrm{hr}$ to completely convert $\mathrm{COOH}$ groups to $\mathrm{COO}^{-}$groups. Finally, the hydrogel particles were thoroughly washed with deionized water and again used in the adsorption experiment. The adsorptiondesorption process was repeated 5 times, and the amount of adsorbed and desorbed metal ions in every cycle was calculated according to Equation 2.

\section{Characterization}

Infrared spectroscopy

Both the CMC and CMC-g-PAA hydrogel before and after $\mathrm{Cu}^{2+}$ adsorption were characterized by FTIR (Mattson 5000 FTIR spectrometer) in the range of $600-4000 \mathrm{~cm}^{-1}$ using $\mathrm{KBr}$ discs. 
$\mathrm{X}$-ray diffraction

$\mathrm{X}$-ray diffraction $(X R D)$ patterns were recorded with an Empyrean Powder Diffractometer $\left(\mathrm{CuK}_{\alpha}, 0.154 \mathrm{~nm}\right)$ between 3 and $70^{\circ} 2 \theta$ with a step size of $0.01 \%$ sec. Samples were mounted on a silicon support.

Scanning Electron Microscopy and Energy-Dispersive X-ray spectroscopy

SEM was carried out on a JEOL JXA-840A Electron probe microanalyzer with tungsten filament $(30 \mathrm{kV})$. For EDX experiments an Oxford INCAx-sight $\mathrm{SN}$ detector with a resolution of $128 \mathrm{eV}$ at $5.9 \mathrm{keV}$ was used.

\section{Results and Discussion}

\section{Optimization of the equilibrium swelling\%}

The data given in Fig.1A show that the highest equilibrium swelling value was achieved at $0.01 \mathrm{~mol} / \mathrm{L}$ of MBA. However, with increasing MBA concentration, the equilibrium swelling gradually decreased, which may be due to increasing the crosslinking density. The high crosslinking density decreases space between co-polymer chains and consequently produces a rigid structure with no ability for expanding to its fullest extent and hence decreases the water absorbance.

The effect of monomer concentration on the equilibrium swelling of the resulting hydrogel was studied. As shown in Fig. 1B, increasing the content of AA led to gradual increasing in the swelling $\%$, where it attained its maximum value $(335 \%)$ at $1.7 \mathrm{~mol} / \mathrm{l}$ then decreased. The swelling-loss after the maximum may be attributed to the higher concentrations of AA which could induce much more chain transfer and termination reactions leading to more homopolymerization instead of copolymerization. In addition, the increase in viscosity of the reaction medium may hinder the movement of the reactants and deactivate the macroradical growing chains after their formation ${ }^{(20)}$.

Figure 1C illustrates the equilibrium swelling of CMC-g-PAA hydrogel as a function of APS concentration. Up to $0.0015 \mathrm{~mol} / \mathrm{l}$, equilibrium swelling increases gradually with APS increasing which may be attributed to increasing number of free radicals. These free radicals can lead to more chain ends on polysaccharide backbone and consequently produce higher graft polymerization extent which increases water absorbetion. In contrast, subsequent decrease in water absorption after $0.0015 \mathrm{~mol} / \mathrm{L}$ can be attributed to increasing the number of produced radicals which may enhance the terminating step via bimolecular collision. As there is an inverse relationship between $\mathrm{Mw}$ and initiator concentration, the increasing in initiator concentration will produce low molecular weight grafted PAA side chains in the formed hydrogel. These short PAA side chains have lower water absorbability. In addition, increasing the number of radicals enhances the crosslinking density described before as selfcrosslinking phenomena ${ }^{(21)}$.

Egypt. J. Chem. 58, No.3 (2015) 
Figure 1D demonstrates the effect of the reaction temperature on the equilibrium swelling of CMC-g-PAA hydrogel. It has been observed that increasing the reaction temperature, beginning from $70^{\circ} \mathrm{C}$ and the water absorbency increased gradually with increasing temperature until $85{ }^{\circ} \mathrm{C}$ where it reached its maximum value (445\%) and then decreased. The increase in swelling can be so explained that high temperatures favor the dissociation of the initiator leading to more copolymerization.
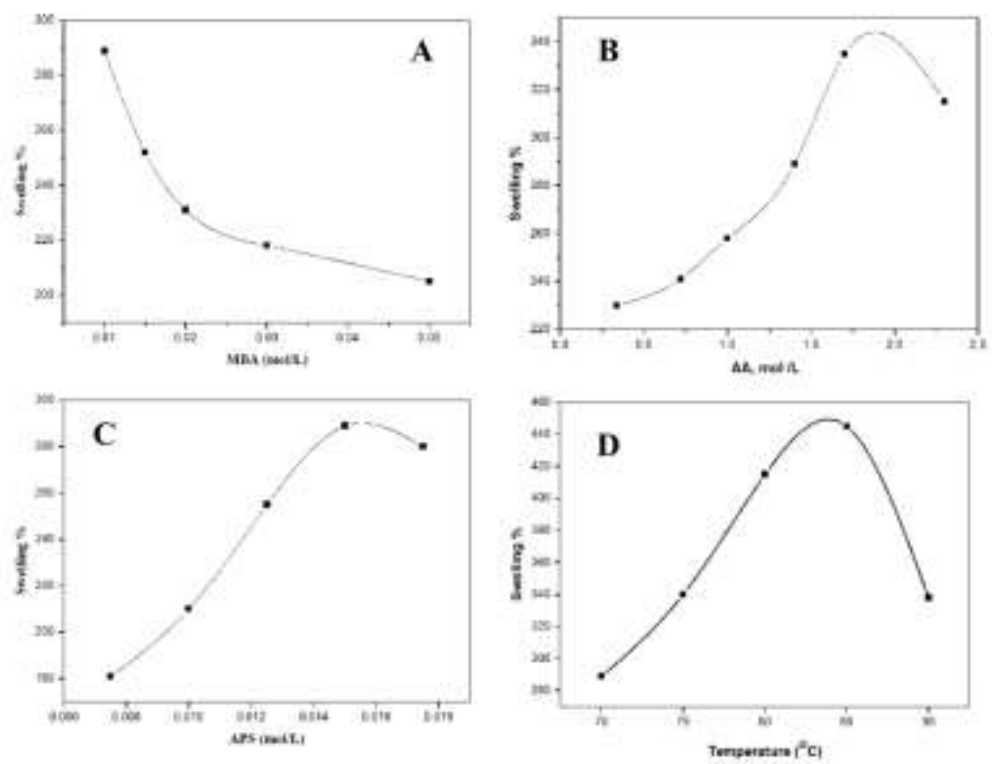

Fig.1. (A)Effect of crosslinker concentration on swelling \% (AA 1.4 mol/L, APS 0.015 $\mathrm{mol} / \mathrm{L}$ at $70^{\circ} \mathrm{C}$ ), (B) Effect of monomer concentration on swelling (MBA 0.01 $\mathrm{mol} / \mathrm{L}$, APS 0.015 mol/L at $70{ }^{\circ} \mathrm{C}$ ), (C) Effect of initiator concentration on swelling \% ( MBA $0.01 \mathrm{~mol} / \mathrm{L}$, AA $1.4 \mathrm{~mol} / \mathrm{L}$ at $70{ }^{\circ} \mathrm{C}$ ), (D) Effect of temperature on swelling \% ( MBA $0.01 \mathrm{~mol} / \mathrm{L}$, AA $1.4 \mathrm{~mol} / \mathrm{L}$ and APS 0.015 $\mathrm{mol} / \mathrm{L} \mathrm{mol} / \mathrm{L}$ ).

\section{$\mathrm{Cu}^{2+}$ ion adsorption study}

CMC-g-PAA hydrogel synthesized at $0.01 \mathrm{~mol} / \mathrm{L} \mathrm{MBA}, 1.7 \mathrm{~mol} / \mathrm{l} \mathrm{AA}$, $0.0015 \mathrm{~mol} / \mathrm{L}$ APS and $85^{\circ} \mathrm{C}$ was evaluated as an adsorbent for $\mathrm{Cu}^{2+}$ ions in the following experiments. Experiments were conducted to determine the optimum conditions for the adsorption of $\mathrm{Cu}^{2+}$ ions on CMC-g-PAA hydrogel. It is expected that the network structure of CMC-g-AA hydrogel permits the adsorption and/or diffusion of the $\mathrm{Cu}^{2+}$. The effect of different parameters will be investigated.

Effect of $p H$ of the initial $\mathrm{Cu}^{2+}$ solution

It is known that the $\mathrm{pH}$ is a critical parameter that can affect the hydrogel performance by influencing its swelling and ion uptake capability ${ }^{(8)}$. The effect of changing the $\mathrm{pH}$ of $\mathrm{Cu}^{2+}$ solution on adsorption capacity of the CMC-g-PAA 
hydrogel is shown in Fig. 2. As can be seen the adsorption capacity increased sharply from $30 \mathrm{mg} / \mathrm{g}$ to a maximum adsorption of $75 \mathrm{mg} / \mathrm{g}$ with increasing $\mathrm{pH}$ of $\mathrm{Cu}^{2+}$ solution from 2 to 5 and then decreased with further increasing the $\mathrm{pH}$ to 6. This phenomenon can be explained as follows: at lower $\mathrm{pH}$ values the carboxylic groups are protonated and metal ions must compete with the protons. On the other hand at higher $\mathrm{pH}$ values, the carboxylic groups of the hydrogel are more ionized, therefore, formation of specific interaction with metal ions is more pronounced. Thus, copper ions are bounded to CMC-g-PAA hydrogel through an ion-exchange mechanism, which involves an electrostatic interaction between copper cations and negatively charged ligands. In addition, a more expanded polymeric network due to the repulsion between negatively charged $\mathrm{COO}^{-}$ groups at higher $\mathrm{pH}$ will also favor the diffusion and adsorption of copper ions in the interior of the hydrogel ${ }^{15}$. However, when the $\mathrm{pH}$ value is higher than 5 the adsorption capacity decreased, due to precipitation of heavy metal ions leading to reduction of its concentration in the aqueous solution ${ }^{(22)}$.

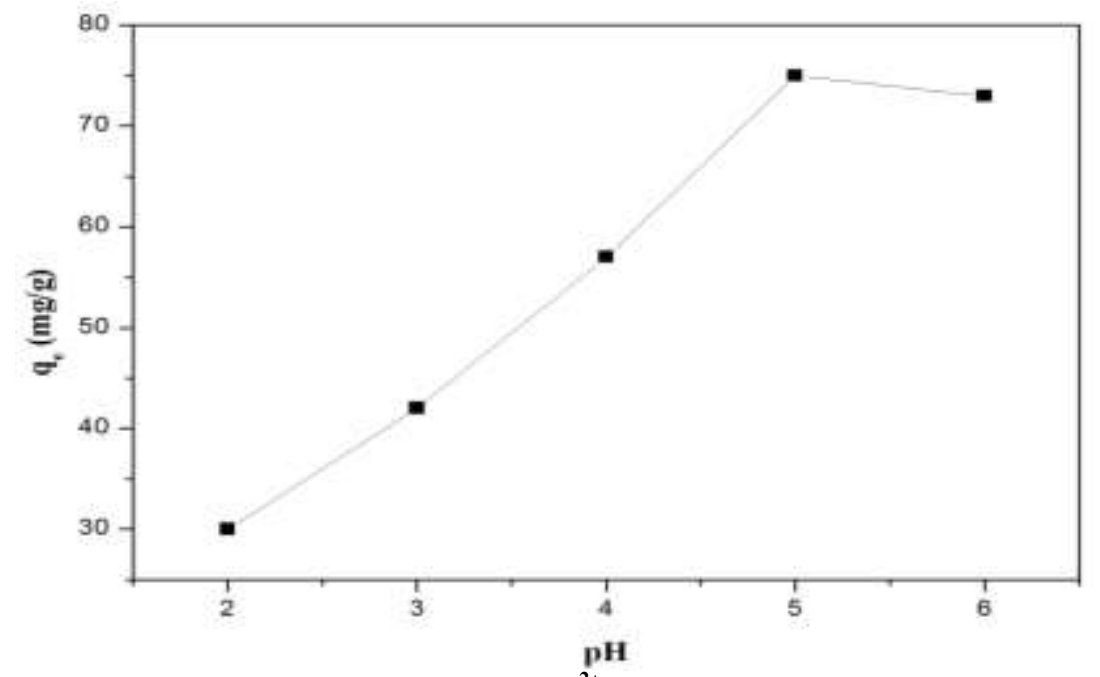

Fig. 2. Effect of $\mathrm{pH}$ on the adsorption of $\mathrm{Cu}^{2+}$ ions on $\mathrm{CMC}$-g-PAA hydrogel (initial concentration $100 \mathrm{mg} / \mathrm{L}$; CMC-g-AA $0.5 \mathrm{~g} / \mathrm{L}$; contact time $120 \mathrm{~min}$; shaking rate $150 \mathrm{rpm})$.

Effect of contact time on the adsorption capacity

To establish the optimum contact time for maximum adsorption capacity and to determine the adsorption kinetics of CMC-g-PAA hydrogel, adsorption of copper ions capacity was measured as a function of time, and the results are shown in Fig. 3. The increase of the adsorption capacity of $\mathrm{Cu}^{2+}$ as contacting time progressed is remarkable and adsorption equilibrium could be achieved within $60 \mathrm{~min}$. The short time period taken to reach the maximum adsorption equilibrium suggests an excellent affinity of the polymeric network toward $\mathrm{Cu}^{2+}$ ions in aqueous solutions. According to this result and the SEM morphologies in

Egypt. J. Chem. 58, No.3 (2015) 
Fig. 7, the following mechanism can be proposed to model the adsorption process: Rapid expansion of the polymeric network starts immediately after immersing the hydrogel in the buffer aqueous solution because of the highly hydrophilic network and strong electrostatic repulsion. Simultaneously, metal ions begin to transport toward the external surface of the hydrogel. This expansion may offer considerable channels for the diffusion of metal ions into the internal pores of hydrogel through the macropores, where they finally are adsorbed. The swelling of hydrogel which resulted from electrostatic repulsion between negatively charged carboxylate ions can favor the diffusion of $\mathrm{Cu}^{2+}$ ions and enhance the adsorption capacity of the adsorbent.

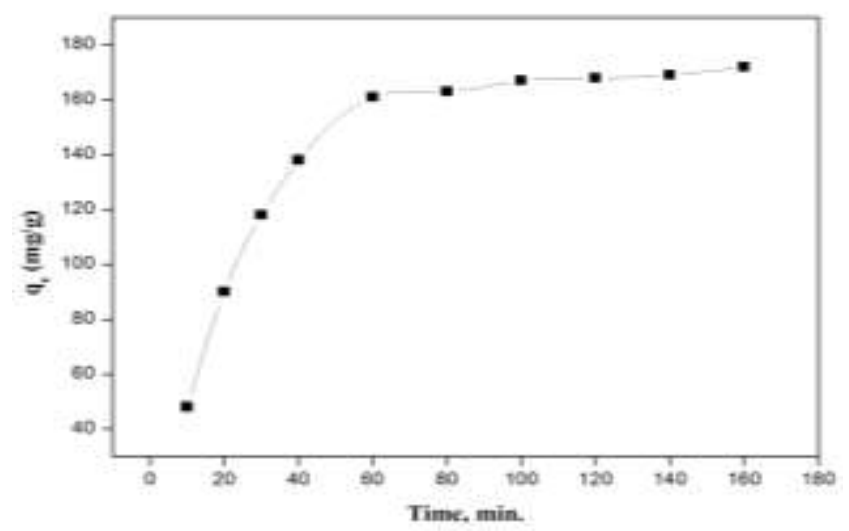

Fig. 3. Effect of contact time on the adsorption of $\mathrm{Cu}^{2+}$ ions on CMC-g-PAA hydrogel (initial concentration $100 \mathrm{mg} / \mathrm{L}$; CMC-g-AA $0.5 \mathrm{~g} / \mathrm{L}$; $\mathrm{pH}$ 5; shaking rate 150 rpm).

To investigate the mechanism of the $\mathrm{Cu}^{2+}$ adsorption process, the two most commonly used kinetic models, i.e., the pseudo-first-order and pseudo-second-order models were used to test the experimental data. The linear pseudo-first-order (Equation 3) and pseudo-second-order (Equation 4) are illustrated as follows:

$$
\begin{gathered}
\log \left(q_{\mathrm{e}}-q_{\mathrm{t}}\right)=\log \left(\mathrm{q}_{\mathrm{e}}\right)-\frac{k_{1}}{2.303} t \\
\frac{t}{q_{t}}=\frac{t}{q_{e}}+\frac{\mathrm{k}}{\mathrm{k}_{2} q_{e}^{2}}
\end{gathered}
$$

where $q_{t}(\mathrm{mg} / \mathrm{g})$ is the adsorption capacity at time $\mathrm{t}(\mathrm{min}), q_{e}(\mathrm{mg} / \mathrm{g})$ is the adsorption capacity at equilibrium and $\left.\mathrm{k}_{1}\left(\mathrm{~min}^{-1}\right)\right)$ and $\mathrm{k}_{2}\left(\mathrm{~g} \mathrm{mg}^{-1} \mathrm{~min}^{-1}\right)$ are the kinetics rate constants for the pseudo-first-order and pseudo-second-order models, respectively. Table 1 lists the computed results obtained from the firstand second-order kinetic models. Clearly, the correlation coefficient $\left(R^{2}\right)$ for the pseudo-second-order kinetic model is higher than that of the pseudo-first-order kinetic model which suggests that this adsorption system is mainly a pseudo second-order kinetic adsorption process and the adsorption is a chemical process. 
TABLE 1. Kinetic parameters for $\mathrm{Cu}^{2+}$ adsorption by CMC-g-PAA hydrogel.

\begin{tabular}{ccccccc}
\hline & \multicolumn{3}{c}{ Pseudo first order-model } & \multicolumn{3}{c}{ Pseudo second- order model } \\
\hline $\mathrm{q}_{\mathrm{e}, \exp }(\mathrm{mg} / \mathrm{g})$ & $\begin{array}{c}\mathrm{q}_{\mathrm{e}, \mathrm{cal}} \\
(\mathrm{mg} / \mathrm{g})\end{array}$ & $\mathrm{K}_{1}\left(\mathrm{~min}^{-1}\right)$ & $\mathrm{R}^{2}$ & $\mathrm{q}_{\mathrm{e}, \text { cal }}(\mathrm{mg} / \mathrm{g})$ & $\mathrm{K}_{2}\left(\mathrm{~g} \mathrm{mg}^{-1} \mathrm{~min}^{-}\right.$ & $\mathrm{R}^{2}$ \\
\hline 171 & 152 & 0.0368 & 0.977 & 200 & $2.292 \times 10^{-4}$ & 0.991 \\
\hline
\end{tabular}

Effect of $\mathrm{Cu}^{2+}$ initial concentration and adsorption isotherms

The experimental data for the adsorption of $\mathrm{Cu}^{+2}$ on CMC-g-PAA hydrogel as a function of the initial $\mathrm{Cu}^{2+}$ concentration are shown in Fig.4. The results clearly indicate that with an increase in initial $\mathrm{Cu}^{2+}$ concentration ( up to $400 \mathrm{mg} / \mathrm{L}$ ), the adsorption capacity increased considerably, almost proportionally with the increment in the initial concentration of the metal ions. This may suggest that the adsorption sites on the gel were sufficient to entrap such amount of the transported metal from the bulk solution. However, at higher initial $\mathrm{Cu}^{+2}$ concentrations $(>400 \mathrm{mg} / \mathrm{l})$, the adsorption capacity no longer increased proportionally with the initial $\mathrm{Cu}^{+2}$ concentration, indicating that the number of the available ligands( carboxylic groups) in the superabsorbent hydrogel really became the limiting factor that controlled the amount of uptake ${ }^{(23)}$.

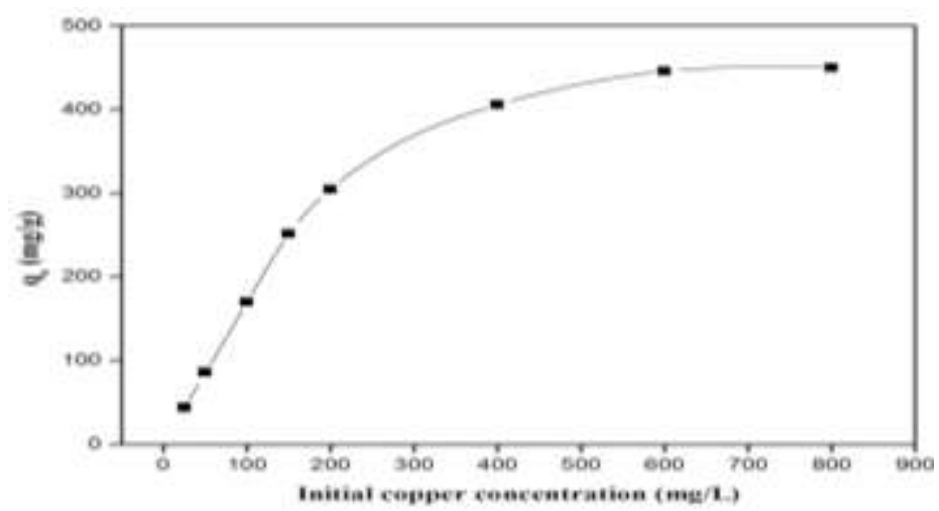

Fig. 4. Adsorption isotherm of $\mathrm{Cu}^{2+}$ by $\mathrm{CMC}$-g-PAA hydrogel at various initial $\mathrm{Cu}^{+2}$ concentrations (initial concentration $25-800 \mathrm{mg} / \mathrm{L}$, CMC-g-PAA $0.5 \mathrm{~g} / \mathrm{L}, \mathrm{pH}$ 5 , shaking rate $150 \mathrm{rpm})$.

The adsorption isotherm was analyzed by fitting the equilibrium data with different isotherm models to investigate the mechanism of adsorption, to describe the interaction between adsorbate and adsorbent molecules and to estimate the extent of adsorption. In this study, Langmuir and Freundlich models were used to determine the adsorption equilibrium between the adsorbent and the metal ion. The isotherm constants for the two models were obtained by linear regression method. The isotherm data are presented in Table 2. The Langmuir ${ }^{(24)}$ isotherm model in the linearized form was calculated according to Equation 5: 


$$
\frac{C_{e}}{q_{e}}=\frac{K_{s}}{q_{\max }}+\frac{C_{e}}{q_{\max }}
$$

where $q_{\mathrm{e}}$ is the equilibrium $\mathrm{Cu}$ adsorption amounts on the hydrogel $(\mathrm{mg} / \mathrm{g}), C_{\mathrm{e}}$ is the equilibrium $\mathrm{Cu}$ concentrations in the solution $(\mathrm{mg} / \mathrm{l}), q_{\max }$ represents the maximum amount of $\mathrm{Cu}$ that could be adsorbed on the hydrogel $(\mathrm{mg} / \mathrm{g})$, and $K_{\mathrm{s}}$ is a constant of the Langmuir model $(\mathrm{mg} / \mathrm{l})$. The high correlation coefficient $\left(\mathrm{R}^{2}=\right.$ 0.999) of the linearized Langmuir equation indicates that the Langmuir model can describe the adsorption of $\mathrm{Cu}^{2+}$ on the CMC-g-PAA hydrogel.

TABLE 2. Parameters for $\mathrm{Cu}^{2+}$ ions adsorption by CMC-g-PAA hydrogel according to different equilibrium models.

\begin{tabular}{cccccc}
\hline \multicolumn{2}{c}{ Langmuir isotherm constants } & \multicolumn{3}{c}{ Freundlish isotherm constants } \\
\hline $\mathrm{K}_{\mathrm{s}}(\mathrm{mg} / \mathrm{L})$ & $\mathrm{q}_{\mathrm{m}}(\mathrm{mg} / \mathrm{g})$ & $\mathrm{R}^{2}$ & $\mathrm{p}(\mathrm{mg} / \mathrm{g})$ & $\mathrm{n}$ & $\mathrm{R}^{2}$ \\
\hline 25.2 & 471 & 0.999 & 46.35 & 2.46 & 0.802 \\
\hline
\end{tabular}

From the slope and the intercept of the straight line, the values of $q_{\max }$ and $K_{\mathrm{s}}$ can be estimated to be $471 \mathrm{mg} / \mathrm{g}$ and $25.2 \mathrm{mg} / \mathrm{l}$, respectively. The Langmuir isotherm model assumes that the adsorbed layer is one molecule in thickness and that all adsorption sites have equal energies and enthalpies of adsorption.

Freundlich model is an empirical model based on adsorption on a heterogeneous surface. The Freundlich equation is given by:

$$
\log q_{e}=\frac{1}{n} \log C_{e}+\log p
$$

where $P$ is a constant representing the adsorption capacity $(\mathrm{mg} / \mathrm{g})$, and $n$ is a constant depicting the adsorption intensity (dimensionless). The plot of $\log q_{\mathrm{e}}$ versus $\log C \mathrm{e}$ for the experimental data illustrated that the correlation coefficient $\left(R^{2}\right)$ for the Freundlich isotherm model is 0.802 , which indicates that this model does not describe very well the adsorption processes of the composite hydrogel for $\mathrm{Cu}^{2+}$. The values of the Freundlich model constants $P$ and $n$ are 46.35 and 2.46 .

The essential features of Langmuir isotherm can be expressed in terms of a dimensionless separation constant factor, $\mathrm{R}_{\mathrm{L}}$, which is used to predict if an adsorption system is favorable or unfavorable. The $\mathrm{R}_{\mathrm{L}}$ value can be estimated according to the following equation:

$$
R_{L}=\frac{1}{1+K s C_{O}}
$$

where $\mathrm{Ks}$ is the Langmuir equilibrium constant and $\mathrm{C}_{\mathrm{o}}(25-800 \mathrm{mg} / \mathrm{L})$ is the initial concentration of $\mathrm{Cu}^{2+}$ ions. The calculated results revealed that the adsorption of $\mathrm{Cu}^{2+}$ ions on CMC-g-AA hydrogels is favorable because all $\mathrm{R}_{\mathrm{L}}$ values were in the range of $0<R_{L}>1$. 
Characterization of CMC-g-PAA before and after $\mathrm{Cu}^{2+}$ adsorption.

The structural changes of CMC and CMC-g-PAA hydrogel before and after copper adsorption were confirmed by FTIR spectroscopy (Fig. 5). Peaks at 1640, 2901 and $3438 \mathrm{~cm}^{-1}$ are related to carboxyl group, asymmetric C-H stretching and O$\mathrm{H}$ stretching vibration in $\mathrm{CMC}$, respectively. However, CMC-g-PAA shows new peaks at 1728,1550 and $1406 \mathrm{~cm}^{-1}$ attributed to carbonyl stretching of the carboxylic acid groups and symmetric and asymmetric stretching modes of carboxylate groups, respectively. As the CMC-g-PAA hydrogel was loaded with $\mathrm{Cu}^{2+}$, the bond energy was altered by the chemical reaction in the adsorption process, which in turn resulted in the decrease of the spectral intensity for the 1710 stretching. This elucidated that $\mathrm{Cu}^{2+}$ had bound with the AA moieties of the CMC-g-PAA hydrogel ${ }^{(25)}$. Moreover, the decrease in the intensity of the peak at $3438 \mathrm{~cm}^{-1}$ after $\mathrm{Cu}^{2+}$ adsorption is an evidence for the binding of $\mathrm{Cu}^{2+}$ ions to the hydroxyl groups. These support that carboxyl groups of the AA moieties and the hydroxyl groups of the CMC are responsible for the $\mathrm{Cu}^{2+}$ adsorption on the hydrogel.

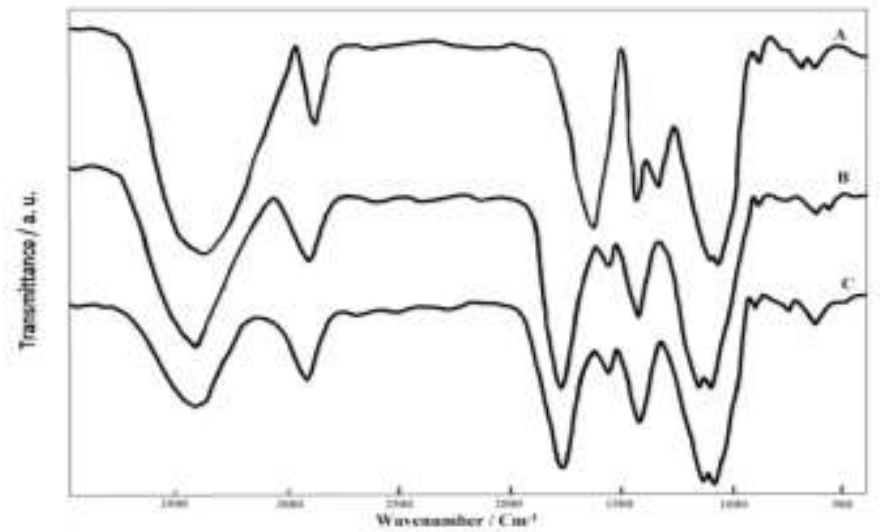

Fig. 5. FT-IR spectra of (A), CMC and CMC-g-PAA hydrogel (B), before and (C), after $\mathrm{Cu}^{2+}$ adsorption.

$\mathrm{X}$-ray diffraction (XRD) is an efficient tool to investigate the degree of crystallinity for polymeric materials ${ }^{(26)}$. XRD patterns for CMC and CMC-g-PAA before and after $\mathrm{Cu}^{2+}$ adsorption are represented in Fig. 6. CMC shows sharp reflections at 9.4 and $20.1^{\circ} 2 \theta$ which are attributed to the partially crystalline structure of the neat CMC. However, these two bands became very marked broad in the CMCg-PAA copolymer indicating its amorphous glassy structure. After $\mathrm{Cu}^{2+}$ adsorption, the broadening of the corresponding peaks was increased.

Figure 7 shows the morphological change of the hydrogel before and after the adsorption of $\mathrm{Cu}^{2+}$. CMC-g-PAA hydrogel exhibited a macroporous 3D structure with a pore diameter of about $80 \mu \mathrm{m}$ (Fig.7A). After the adsorption of $\mathrm{Cu}^{2+}$ ions, the expanded pores completely collapsed, and no pores could be observed on the surface of CMC-g-PAA hydrogel (Fig. 7B). The presence of $\mathrm{COO}^{-}$groups in CMC-g-PAA hydrogel produces strong electrostatic repulsion in water, thus, the expansion of polymer chains occurs, forming a macroporous structure. The 
interaction between electronegative $\mathrm{COO}^{-}$groups and electropositive metal ions results in the electrostatic screening of anionic groups $\left(\mathrm{COO}^{-}\right)$in the polymeric network, which leads to the decrease in electrostatic repulsion and the shrinkage of the network or pores. The expansion of the polymeric network and porous structure in the initial adsorption stage favors the diffusion and adsorption of metal ions from the exterior to the interior of the hydrogel. In addition, The results of EDX for the CMC-g-PAA before and after $\mathrm{Cu}^{2+}$ adsorption were displayed under SEM micrograph, it is difficult to extract clear evidence about $\mathrm{Cu}^{2+}$ in the adsorbed hydrogel, only atomic\% for each sample is given.

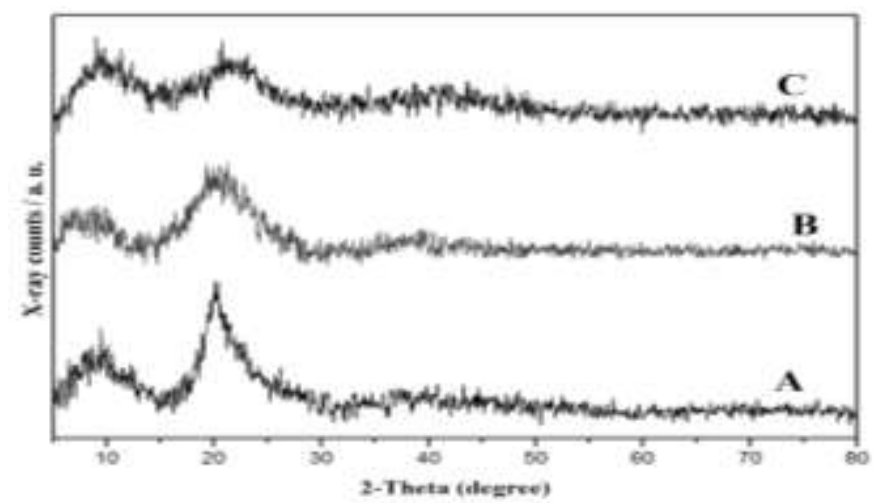

Fig. 6. XRD patterns of (A), CMC (B), CMC-g-PAA hydrogel and (C), copper adsorbed CMC-g-PAA hydrogel samples.
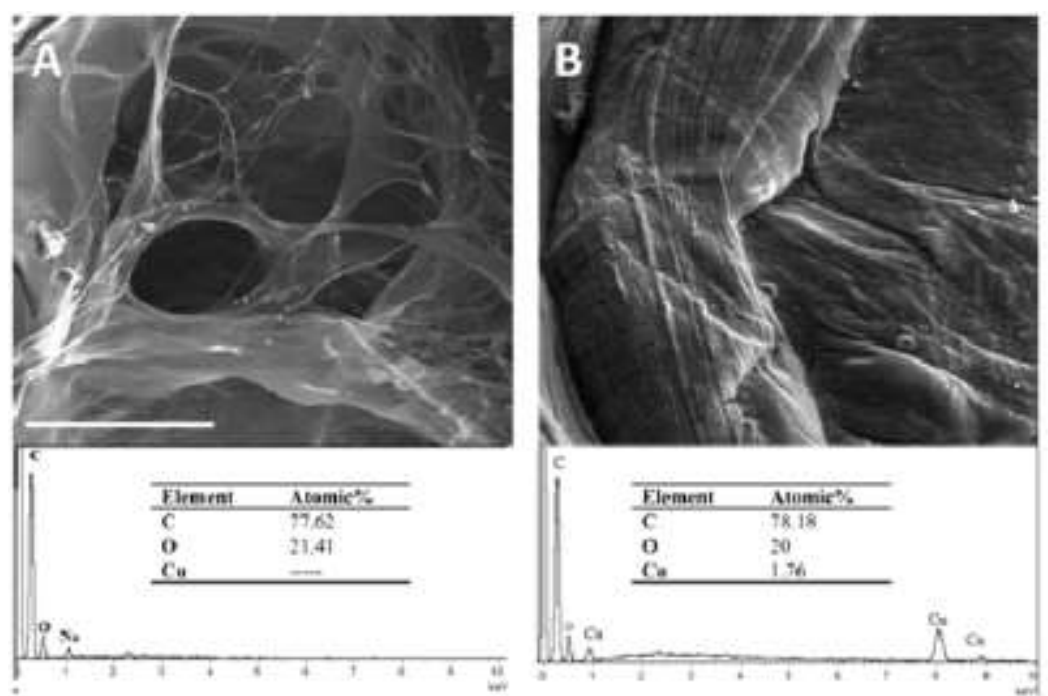

Fig. 7. SEM micrographs and corresponding representative EDX patterns of CMCg-PAA hydrogel (A), before and (B), after the adsorption process in $\mathrm{Cu}^{2+}$ ions solutions( Scale bar $=\mathbf{2 0 0} \mu \mathrm{m})$. 
Desorption and reusability

Table 3 illustrates the adsorption and desorption behaviors of CMC-g-PAA hydrogel for five cycles. The adsorption capacity of $\mathrm{Cu}^{2+}$ was $390 \mathrm{mg} / \mathrm{g}$, after five cycles, indicating that reuse has little influence on the metal ion uptake. The recovery efficiency was high up to $98.4 \%$ in the first cycle and then slightly decreased to $96.3 \%$ after five cycles. In $0.5 \mathrm{M} \mathrm{HNO}_{3}$ solution, the protons compete with metal ions for carboxyl groups, which is responsible for the easy desorption of metal ions. This again confirms that the main adsorption mechanism is ion exchange. Therefore, CMC-g-PAA hydrogel has stable physical and chemical properties and can be reused almost without significantly decreasing the adsorption capability after quite a number of cycles.

TABLE 3.The adsorption ratio of reused CMC-g-PAA hydrogel in consecutive five adsorption-desorption cycles.

\begin{tabular}{lcc}
\hline & Adsorption capacity of Cu ${ }^{2+}$ & ${\text { Recovery rate (desorption) of } \mathbf{C u}^{2+}}^{\mathbf{2}^{+}}$ \\
\hline Cycle 1 & 450 & 98.4 \\
\hline Cycle 2 & 443 & 98.2 \\
\hline Cycle 3 & 435 & 96.5 \\
\hline Cycle 4 & 420 & 96.3 \\
\hline Cycle 5 & 405 & 96.3 \\
& 390 & \\
\hline
\end{tabular}

\section{Conclusion}

CMC-g-PAA hydrogel was synthesized and characterized as adsorbent for removal of $\mathrm{Cu}^{2+}$ from waste water. The experimental data showed that CMC-gPAA prepared at optimum conditions exhibited high adsorption performance for copper ions in solution at $\mathrm{pH}$ 5. Equilibrium isotherm data were found to conform to Langmuir model with a good correlation. Kinetic study showed that the pseudo-second order model is appropriate to describe the adsorption process which demonstrates that the mechanism of adsorption includes mainly ionic interactions between $\mathrm{Cu}^{2+}$ and the carboxylate anions of the CMC-g-PAA hydrogel. The adsorption-desorption cycle results indicate that the regeneration and subsequent use would enhance the economics of the hydrogel applications in waste water treatment.

Acknowledgment: This work was supported by the National Research Center in Cairo, Egypt. Project of Cellulose and Paper Department (No. 10130101).

\section{References}

1. O'Connell, D. W., Birkinshaw, C. and O'Dwyer, T. F., Heavy metal adsorbents prepared from the modification of cellulose: A review. Bioresour. Technol. 99, 67096724 (2008).

Egypt. J. Chem. 58, No.3 (2015) 
2. Hoai, N. T., Yoo, D.K. and Kim, D., Batch and column separation characteristics of copper-imprinted porous polymer micro-beads synthesized by a direct imprinting method. J. Hazard. Mater. 173, 462-467 (2010).

3. Ng, J. C., Cheung, W. and McKay, G., Equilibrium studies of the sorption of $\mathrm{Cu}(\mathrm{II})$ ions onto chitosan. J. Colloid Interface Sci. 255, 64-74 (2002).

4. Jellouli Ennigrou, D., Ben Sik Ali, M. and Dhahbi, M., Copper and zinc removal from aqueous solutions by polyacrylic acid assisted-ultrafiltration. Desalination, 343, 82-87 (2014).

5. Ahluwalia, S. S. and Goyal, D., Removal of heavy metals by waste tea leaves from aqueous solution. Eng. Life Sci. 5, 158-162 (2005).

6. Wang, L., Zhang, J. and Wang, A., Fast removal of methylene blue from aqueous solution by adsorption onto chitosan-g-poly (acrylic acid)/attapulgite composite. Desalination, 266, 33-39 (2011).

7. Abdel-Halim, E.S., Preparation of starch/poly (N,N- diethylaminoethyl methacrylate) hydrogel and its use in dye removal from aqueous solutions. React. Funct. Polym. 73, 1531-1536 (2013).

8. Hajeeth, T., Vijayalakshmi, K., Gomathi, T. and Sudha, P. N., Removal of $\mathrm{Cu}(\mathrm{II})$ and $\mathrm{Ni}(\mathrm{II})$ using cellulose extracted from sisal fiber and cellulose-g-acrylic acid copolymer. Int. J. Biol. Macromol. 62, 59-65 (2013).

9. Rayford, W.E., Wing, R.E. and Doane, W.M., Carboxyl- containing starch graft polymer: Preparation and use in heavy metal removal. J. Appl. Polym. Sci. 24, 105-113 (1979).

10. Narayan, S., Dani, H.M. and Misra, U.K., Changes in lipid profiles of liver microsomes of rats following intratracheal administration of DDT or endosulfan. $J$. Environ. Sci. Health. B. 25, 243-257 (1990).

11. Ertaş, M., Acemioğlu, B., Alma, M. H. and Usta, M., Removal of methylene blue from aqueous solution using cotton stalk, cotton waste and cotton dust. J. Hazard. Mater. 183, 421-427 (2010).

12. Monier, M. and Abdel-Latif, D. A., Synthesis and characterization of ion-imprinted resin based on carboxymethyl cellulose for selective removal of $\mathrm{UO}_{2}{ }^{2+}$. Carbohydr. Polym. 97, 743-52 (2013).

13. Zhang, J. and Wang, A., Adsorption of $\mathrm{Pb}$ (II) from aqueous solution by chitosan- g -poly ( acrylic acid )/ attapulgite / sodium humate composite hydrogels. J. Chem. Eng. Data, 55, 2379-2384 (2010).

14. Monier, M., Ayad, D. M., Wei, Y. and Sarhan, A. A., Adsorption of Cu(II), Co(II), and $\mathrm{Ni}(\mathrm{II})$ ions by modified magnetic chitosan chelating resin. J. Hazard. Mater. 177, 962-70 (2010).

15. Peng, X.W., Zhong, L.X., Ren, J.L. and Sun, R.C., Highly effective adsorption of heavy metal ions from aqueous solutions by macroporous xylan-rich hemicellulosesbased hydrogel. J. Agric. Food Chem. 60, 3909-16 (2012).

Egypt. J. Chem. 58, No. 3 (2015) 
16. Li, N. and Bai, R., Copper adsorption on chitosan-cellulose hydrogel beads: Behaviors and mechanisms. Sep. Purif. Technol. 42, 237-247 (2005).

17. Wang, M. et al. $\gamma$-ray radiation-induced synthesis and Fe(III) ion adsorption of carboxymethylated chitosan hydrogels. Carbohydr. Polym. 74, 498-503 (2008).

18. Vermonden, T., Censi, R. and Hennink, W.E., Hydrogels for protein delivery. Chem. Rev. 112, 2853-2888 (2012).

19. Salama, A., Shukry, N. and El-Sakhawy, M., Carboxymethyl cellulose-g-poly(2(dimethylamino) ethyl methacrylate) hydrogel as adsorbent for dye removal. Int. J. Biol. Macromol. 73, 72-75 (2015).

20. Pourjavadi, A., Sadeghi, M. and Hosseinzadeh, H., Modified carrageenan. 5 Preparation, swelling behavior, salt- and pH-sensitivity of partially hydrolyzed crosslinked carrageenan-graft-polymethacrylamide superabsorbent hydrogel. Polym. Adv. Technol. 15, 645-653 (2004).

21. Chen, J. and Zhao, Y., Relationship between water absorbency and reaction conditions in aqueous solution polymerization of polyacrylate superabsorbents. $J$. Appl. Polym. Sci. 75, 808-814 (2000).

22. Feng, Y. et al., Adsorption of Cd (II) and Zn (II) from aqueous solutions using magnetic hydroxyapatite nanoparticles as adsorbents. Chem. Eng. J. 162, 487-494 (2010).

23. Li, N. and Bai, R., Highly enhanced adsorption of lead ions on chitosan granules functionalized with poly(acrylic acid). Ind. Eng. Chem. Res. 45, 7897-7904 (2006).

24. Periasamy, K. and Namasivayam, C., Removal of nickel(II) from aqueous solution and nickel plating industry wastewater using an agricultural waste: Peanut hulls. Waste Manag. 15, 63-68 (1995).

25. Chen, J. J., Ahmad, A. L. and Ooi, B. S., Poly(N-isopropylacrylamide-co-acrylic acid) hydrogels for copper ion adsorption: Equilibrium isotherms, kinetic and thermodynamic studies. J. Environ. Chem. Eng. 1, 339-348 (2013).

26. Segal, L., Creely, J. J., Martin, A. E. and Conrad, C. M., An empirical method for estimating the degree of crystallinity of native cellulose using the X-ray diffractometer. Text. Res. J. 29, 786-794 (1959). 


$$
\begin{aligned}
& \text { هلاميات من الكريوكسى ميثيل سليلوز المطعم بحمض الأكريلك }
\end{aligned}
$$

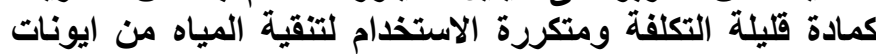

$$
\begin{aligned}
& \text { النحاس الثنائية }
\end{aligned}
$$

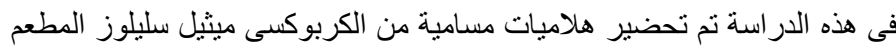

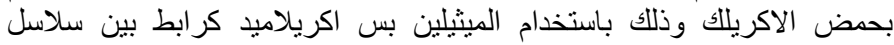

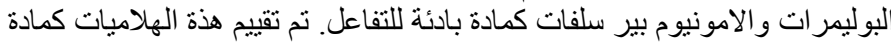

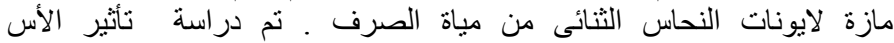

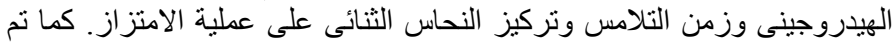

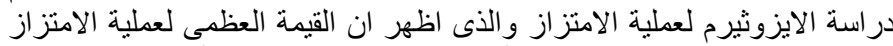

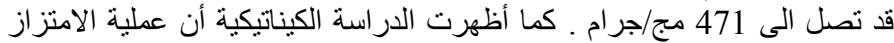

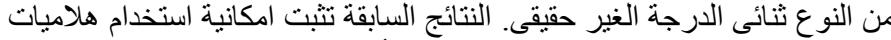

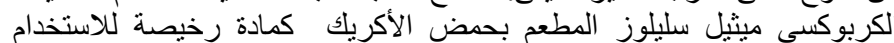

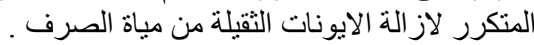

